\title{
Fungicidas e argila silicatada no controle da antracnose do maracujá amarelo
}

\section{Fungicides and silicate clay on the control of antracnosis in yellow passionfruit}

\author{
André Martins de Medeiros ${ }^{1}$; Luiz Augusto Martins Peruch ${ }^{2}$
}

Resumo

A antracnose, causada por Glomerella cingulata (anamorfo Colletotrichum gloesporioides), é a principal doença fúngica de parte aérea do maracujazeiro amarelo. Todavia, poucos estudos de controle da doença a campo têm sido publicados, motivo pelo qual é importante avaliar diferentes fungicidas e substâncias alternativas para o manejo da antracnose. Neste trabalho foram avaliados os seguintes tratamentos: tebuconazole (20g i.a./100L), oxicloreto de cobre (180g i.a./100L), argila silicatada (15g/L) e testemunha. A partir da avaliação da severidade da doença, determinou-se a área abaixo da curva de progresso da doença (AACPD), severidade final (SEVF) e as curvas de progresso da doença. O delineamento adotado foi inteiramente casualizado com cinco repetições. Tebuconazole e argila silicatada proporcionaram os melhores resultados no controle da doença pela redução significativa da AACPD e SEVF em relação à testemunha. Oxicloreto de cobre diferiu da testemunha apenas para SEVF. Tratamento com tebuconazole reduziu AACPD e SEVF em $75 \%$ e $71 \%$, e argila silicatada em $82 \%$ as variáveis, respectivamente. Oxicloreto de cobre reduziu SEVF em $76 \%$. As curvas de progresso da doença corroboram os resultados pelo menor crescimento da antracnose para tebuconazole e da argila silicatada. O Tebuconazole e a argila silicatada são eficientes no controle da antracnose do maracujazeiro.

Palavras-chave: Passiflora edulis f. flavicarpa, Colletotrichum gloeosporioides, pó de rocha, oxicloreto de cobre, tebuconazole

\begin{abstract}
The anthracnose, caused by Glomerella cingulata (anamorf Colletotrichum gloeosporioides), is the most important fungal disease for aerial parts of yellow passionfruit. However, few studies about anthracnose control in field conditions have been published. The objective of this research was to evaluate silicate clay and fungicides for anthracnose control. Treatments evaluated were: tebuconazole (20g i.a./100L), copper oxychloride (180g i.a./100L), silicate clay $(15 \mathrm{~g} / \mathrm{L}$ ) and control (untreated plants). The sanity of the plants was evaluated through area under disease progress curve (AUCPD), final severity (SEVF) and disease progress curves. Experimental design was completely randomized with five repetitions. Tebuconazole and silicate clay proportioned significant reduction for AUCPD and SEVF compared to control. Copper oxychloride reduced only SEVF. Treatment with tebuconazole reduced AUCPD and SEVF in $75 \%$ and $71 \%$, and silicate clay in $82 \%$, respectively. Copper oxychloride reduced SEVF in $76 \%$. The disease progress curves confirmed results and showed lower growth of anthracnose for tebuconazole and silicate clay. Silicate clay and tebuconazole are efficient to control anthracnose in passionfruit.

Key words: Passiflora edulis f. flavicarpa, Colletotrichum gloeosporioides, rock powder, copper oxychloride, tebuconazol
\end{abstract}

\footnotetext{
${ }^{1}$ Eng $^{\text {o }}$ Agr ${ }^{\circ}$, Autônomo, Tubarão, SC. E-mail: andremartinsdemedeiros@yahoo.com.br

${ }^{2}$ Eng $^{\mathrm{o}} \mathrm{Ag}^{\mathrm{o}}$, Dr. Pesquisador, Epagri/Estação Experimental de Urussanga, Unibave/Núcleo PACA, Urussanga, SC. E-mail: lamperuch@epagri.sc.gov.br

* Autor para correspondência
} 
O maracujá amarelo (Passiflora edulis f. flavicarpa) é uma das principais frutas tropicais cultivadas no Brasil. Em 2006, a cultura ocupava uma área de 44.363 ha, com produção anual estimada de 615.196 mil toneladas, destacandose a Bahia, Ceará, Pará e Sergipe como principais Estados produtores (IBGE, 2007). Em Santa Catarina, os pomares da cultura ocupavam cerca de 447 ha em 2007, distribuídos principalmente nas regiões do Litoral Sul, Norte e Central Catarinense (PERUCH et al., 2009). Nos últimos anos houve de aumento das áreas de produção desta frutífera no Estado de Santa Catarina. Isto ocorreu em virtude da queda de produção em outros Estados produtores, especialmente nas regiões Sudeste e Nordeste.

Vários fatores podem influenciar a produtividade desta frutífera, tais como a polinização, tipos e quantidade de fertilizantes, fatores climáticos, entre outros. Dentre estes, as doenças apresentam um papel relevante na produtividade dos pomares e qualidade da fruta, sendo, inclusive, responsáveis pelo declínio da cultura em certas regiões do Brasil (FISCHER; KIMATI; REZENDE, 2005). As doenças mais importantes do maracujazeiro amarelo no Brasil são: o endurecimento do fruto (CABMV e PWV), a mancha oleosa (Xanthomonas axonopodis pv. passiflorae), a fusariose (Fusarium oxysporum f.sp. passiflorae e $F$. solani) e a antracnose (Glomerella cingulata) (FISCHER; KIMATI; REZENDE, 2005).

A antracnose, causada pelo fungo $G$. cingulata (anamorfo Colletotrichum gloeosporioides Penz. Sacc.), é considerada a principal doença fúngica de parte aérea da cultura, tendo sido responsável por grandes perdas nos pomares catarinenses no campo e na pós-colheita (PERUCH et al., 2009). A doença provoca sintomas em toda a parte aérea da planta, destruindo folhas, frutos e ramos. Os sintomas nas folhas são manchas formato irregular, marrom claras a escuras e bordos indefinidos. Sobre as manchas podem ser observados pequenos pontos pretos (acérvulos) na face superior e/ou inferior da folha. Nos frutos formam-se manchas superficiais circulares ou irregulares, de coloração creme a marrom clara, com bordos úmidos e indefinidos. Estas lesões evoluem para podridões de cor marrom claro a escuro, deprimidas e com bordos encharcados. Nos ramos, a doença forma cancros irregulares, de coloração esbranquiçada a creme. $\mathrm{O}$ avanço da lesão nos ramos pode provocar os sintomas de secamento dos mesmos e morte dos ponteiros.

Adubações equilibradas, podas de limpeza, manejo do pomar e a pulverização de fungicidas são algumas das práticas de controle recomendadas para antracnose do maracujazeiro. Nesse patossistema, o controle integrado tem grande importância, pois o controle químico com fungicidas aplicado como medida isolada não tem sido eficiente na redução das perdas provocadas pela antracnose (PERUCH et al., 2009). Os fungicidas registrados para cultura são formulações à base de cobre, triazol, benzimidazol e estrobilurina (BRASIL, 2011). Todavia, deve-se ressaltar que o número de moléculas disponíveis para pulverização no maracujazeiro ainda é restrita. Apesar do recente registro de estrobirulina + triazol para a cultura, ainda são necessários mais estudos sobre novos fungicidas para o maracujazeiro.

Atualmente, a pesquisa tem avaliado inúmeras substâncias alternativas no controle de doenças, destacando-se os extratos vegetais, substâncias homeopáticas, biofertilizantes, entre outros. A técnica de rochagem, que consiste da aplicação de pós de rocha como fonte de nutrientes foi estudada quanto ao seu efeito na produtividade e controle de insetos de algumas culturas (MELAMED; GASPAR; MIEKELY, 2007; MICHALOVICZ et al., 2009), mas pouco se conhece sobre sua aplicação no controle de doenças de plantas. Alguns pós de rocha podem ser encontrados no mercado, mas a maioria das formulações testadas em experimentos pertence a fontes locais. Um pó de rocha silicatada comercial foi testada por Branchaglione et al. (2009) que verificaram resultados positivos no controle da bacteriose do maracujazeiro. 
O controle proporcionado por estas substâncias alternativas é relacionados com a nutrição vegetal e a indução de resistência. De forma geral, o efeito de determinados nutrientes no controle de algumas doenças é bem conhecido, especialmente para o nitrogênio e o potássio. Mais recentemente, o papel do silício vem sendo estudado no controle de doenças. Nas plantas, o silício participa no fortalecimento da camada de células epidérmicas, formando barreira física contra a penetração das hifas dos fungos (MARSCHNER, 1995). Por outro lado, o silício também pode atuar na indução de resistência pela ativação dos mecanismos de defesa das plantas tratadas com fontes ricas deste nutriente (RODRIGUES et al., 2004).

O objetivo deste trabalho foi avaliar o efeito do oxicloreto de cobre, tebuconazole e argila silicatada comercial no controle da antracnose do maracujazeiro em campo.

No período de Setembro a Novembro de 2007, o experimento foi conduzido em um pomar comercial adulto de 1ha no município de Jacinto Machado, Santa Catarina (SC), situado na comunidade de Dois Irmãos.

Foram testados quatro tratamentos: tebuconazole-Folicur $200 \mathrm{CE}(20 \mathrm{~g}$ i.a./100L), oxicloreto de cobre- Agrinose ${ }^{\circledR}$ (180g i.a./100L), argila silicatada comercial $(15 \mathrm{~g} / \mathrm{L})$, contendo $20 \% \mathrm{Al}_{2} \mathrm{O}_{3}, 17,43 \% \mathrm{SiO}_{2}, 9,82 \% \mathrm{~S}, 1,31 \% \mathrm{CaO}$, 0,34\% $\mathrm{TiO}_{2}, 0,18 \% \mathrm{MgO}, 0,16 \% \mathrm{Fe}_{2} \mathrm{O}_{3}, 0,10 \%$ $\mathrm{P}_{2} \mathrm{O}_{5}$.), além da testemunha. As pulverizações foram efetuadas quinzenalmente, com início em 18/09/2007, estendendo-se até o final de novembro. As pulverizações foram efetuadas por pulverizador costal, com bico tipo cone cheio e volume de calda variando de 1.200-1.850 L/ha, conforme o estádio de desenvolvimento das plantas.

As parcelas foram compostas por três plantas adultas, com um ano de idade, conduzidas no sistema de espaldeira e com espaçamento de 1,5 x $3 \mathrm{~m}$. A área útil da parcela foi composta pela planta central. As plantas foram manejadas segundo sistema de produção da cultura (BRUCKNER; PICANÇO, 2001).

$\mathrm{O}$ efeito dos tratamentos foi determinado pela avaliação da doença nas folhas de três ramos previamente marcados em cada parcela útil, ou seja, na planta central. A severidade da antracnose nas folhas foi quantificada em dez folhas dos ramos marcados em porcentagem da área foliar acometida, a saber: 0, 10, 25 e 50\%. As avaliações foram efetuadas em seis ocasiões, com intervalos de sete dias entre elas. Com os dados de severidade foi determinada a área abaixo da curva de progresso da doença (AACPD) e a severidade final aos 42 dias (SEVF). A AACPD foi calculada pela expressão: AACPD $=\mathrm{S}\left(\mathrm{y}_{\mathrm{i}}+\mathrm{y}_{\mathrm{i}+1}\right) / 2 \cdot \mathrm{d}_{\mathrm{ti}}$, onde $\mathrm{y}_{\mathrm{i}}$ e $\mathrm{y}_{\mathrm{i}+1}$ representaram os valores de severidade observados em duas avaliações consecutivas e $d_{\mathrm{ti}} \mathrm{O}$ intervalo entre as avaliações (SHANER; FINNEY, 1977). A severidade final (SEVF) é a última avaliação da doença realizada aos 42 dias após primeira pulverização das plantas. Ainda, curvas de progresso da doença foram confeccionadas para facilitar a interpretação dos dados.

O delineamento experimental adotado foi o inteiramente casualizado com quatro repetições. Os dados foram submetidos à análise de variância e a comparação de médias pelo Teste de Duncan (P£0,05). As análises estatísticas foram realizadas pelo programa SAEG (RIBEIRO JÚNIOR, 2001).

De acordo com os resultados de AACPD, os melhores tratamentos foram argila silicatada e tebuconazole que proporcionaram redução da severidade da doença em 82 e 75\%, respectivamente, em relação à testemunha (Tabela 1). Para todos os produtos utilizados, os valores de severidade final, correspondente à última avaliação de severidade no período (aos 42 DAPT, dias após primeiro tratamento), foram menores quando comparados à testemunha, correspondendo a reduções de 82,77 e $71 \%$ para argila silicatada, oxicloreto de cobre e tebuconazole, respectivamente. 
Tabela 1. Área abaixo da curva de progresso da doença (AACPD) e severidade final da antracnose (Glomerella cingulata, anamorfo Colletotrichum gloeosporioides) do maracujazeiro amarelo submetidos a diferentes tratamentos em Jacinto Machado-SC, 2007.

\begin{tabular}{ccc}
\hline Tratamento & AACPD $^{1,4}$ & Severidade aos 42 DAPT D, $^{3,4}$ \\
\hline Testemunha & $58,2 \mathrm{~A}$ & $3,9 \mathrm{~A}$ \\
Oxicloreto de cobre $(0,3 \%)$ & $35,9 \mathrm{AB}$ & $0,9 \mathrm{~B}$ \\
Tebuconazol $(0,1 \%)$ & $14,4 \mathrm{~B}$ & $1,1 \mathrm{~B}$ \\
Argila silicatada $(1,5 \%)$ & $10,4 \mathrm{~B}$ & $0,7 \mathrm{~B}$ \\
C.V. $(\%)$ & 20,4 & 30,1 \\
\hline P $\geq 0,5$ & 0,02 & 0,04 \\
\hline
\end{tabular}

${ }^{1}$ AACPD: valores reais de AACPD determinados pela severidade em seis avaliações com intervalos de sete dias. Análise com dados transformados para raiz x para análise de variância

${ }^{2} \mathrm{DESF}=$ Porcentagem de desfolha em 50 folhas de cinco ramos aos 42 dias após primeiro tratamento (DAPT)

${ }^{3} \mathrm{SEVF}=$ Porcentagem de área lesionada em 50 folhas de cinco ramos aos 42 DAPT

${ }^{4}$ Letras diferentes denotam diferenças significativas entre os tratamentos pelo teste de Duncan ao nível de $5 \%$ de probabilidade

Fonte: Elaboração dos autores.

$\mathrm{Na}$ curva de progresso da doença verifica-se comportamento similar entre os tratamentos até os 14 DAPT. Todavia, aos 21 dias, percebe-se incremento dos valores de severidade da testemunha em relação aos demais tratamentos (Figura 1). Este comportamento se intensifica nas avaliações posteriores e a severidade avança mais rapidamente nas plantas não tratadas em comparação aos outros tratamentos. A análise das curvas de progresso permite afirmar que seu comportamento concorda com os resultados verificados para as variáveis da AACPD e SEVF, pois os valores de severidade mostraram-se reduzidos nas parcelas que foram tratadas com argila silicatada ou fungicida.

Figura 1. Curva de progresso da antracnose (Glomerella cingulata, anamorfo Colletotrichum gloeosporioides) do maracujazeiro amarelo submetidos a diferentes tratamentos no período de 42 dias após primeiro tratamento (DAPT) em Jacinto Machado-SC, 2007.

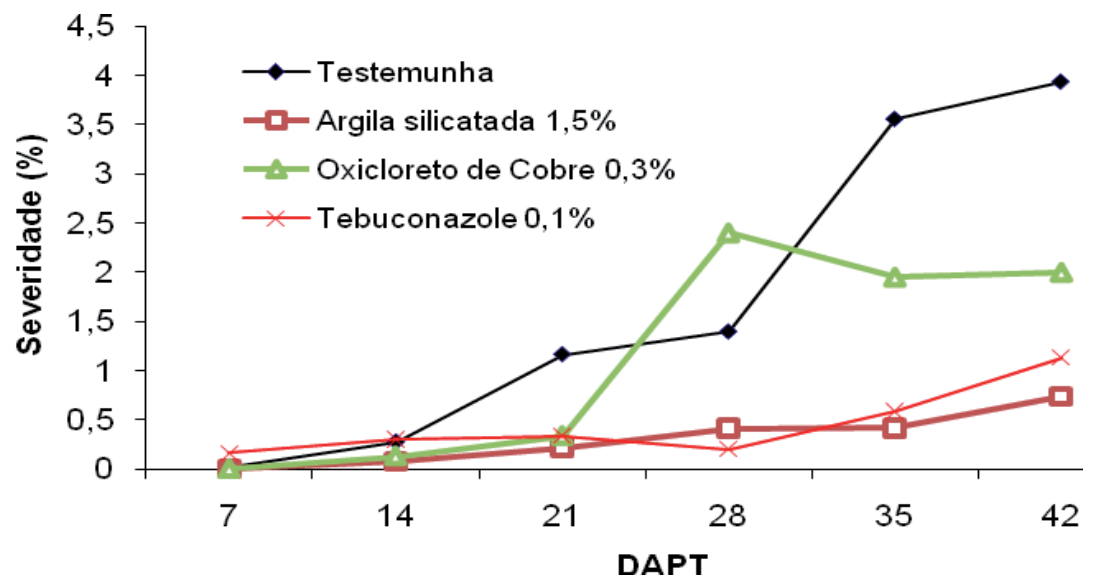

Fonte: Elaboração dos autores. 
Levando-se em consideração as análises pode-se afirmar que o tratamento com oxicloreto de cobre apresentou controle intermediário da doença. Muito embora vários fungicidas a base de oxicloreto de cobre não tenham mais registro para cultura, estes ainda são usados regularmente na cultura do maracujazeiro para o controle da bacteriose. Em diferentes experimentos em campo, Rheinländer; Fullerton e Sale (2009) verificaram que a aplicação de um programa de pulverizações na cultura somente com oxicloreto de cobre nem sempre proporciona níveis adequados de controle das doenças. No entanto, considera-se que seu uso é fundamental no programa de rotação de fungicidas e no controle das bacterioses do maracujazeiro (RHEINLÄNDER; FULLERTON; SALE, 2009).

Os resultados obtidos a partir do uso de tebuconazole concordam com os vários experimentos descritos em literatura e que comprovaram sua eficiência no controle da doença no maracujazeiro (ALMEIDA et al., 1994).

A argila silicatada proporcionou redução da severidade da doença e isso se deve, possivelmente, pela presença de enxofre, silício e cálcio da fórmula. O enxofre faz parte de algumas recomendações de controle da antracnose, muito embora não tenha registro para a cultura (PIO RIBEIRO; MARIANO, 1995) e, além disso, o elemento está relacionado com o aumento da produtividade dos pomares de maracujá (SANTOS et al., 2007). Ainda com relação a utilização de argila silicatada, Branchaglione et al. (2009) recomendaram doses de 1,0 a 2,0\% para controle da bacteriose em plantas de maracujazeiro.

Pulverizações com oxicloreto de cálcio (2\%) na parte aérea do maracujazeiro também podem resultar em redução da antracnose (PERUCH et al., 2009). Além do efeito fungitóxico direto, não se pode desprezar o efeito nutricional do cálcio no aumento da produtividade (SANTOS et al., 2007).

Deve-se ressaltar que os resultados com silicatos no controle de doenças em diferentes culturas são muito variáveis. Por este motivo é importante aprofundar os estudos com a argila silicatada a fim de determinar doses e períodos de aplicação para melhor eficiência do produto.

De acordo com os resultados obtidos verificou-se que argila silicatada e o tebuconazole são eficientes no controle da antracnose no maracujazeiro; enquanto o oxicloreto de cobre foi medianamente eficiente para doença.

\section{Referências}

ALMEIDA, A. M.; NOGUEIRA, E. M. de C.; FERRARI, J. T.; MARTINS, G. A. Controle químico da antracnose (Colletotrichum gloeosporioides) do maracujá (Passiflora edulis f. flavicarpa). Fitopatologia Brasileira, Brasília, v. 19, p. 182, 1994. Suplemento.

BRANCHAGLIONE, P.; SAMPAIO, A. C.; FISCHER, I. H.; ALMEIDA, A. M. de; FUMIS, T. F. Eficiência da argila silicatada no controle de Xanthomonas axonopodis pv. passiflorae in vitro e mudas de maracujazeiro. Revista Brasileira de Fruticultura, Jaboticabal, v. 31. n. 3, p. 718-724, 2009.

BRASIL. Agrofit. 2011. Disponível em: <http://www. agrofit.agricultura.gov.br/agrofit_cons/principal_ agrofit_cons $>$. Acesso em: $20 \mathrm{dez} .2011$.

BRUCKNER, C. H.; PICANÇO, M. C. Maracujá: tecnologia de produção, pós-colheita, agroindústria e mercado. Porto Alegre: Cinco Continentes, 2001. 472 p.

FISCHER, I. H.; KIMATI, H.; REZENDE, J. A. M. Doenças do Maracujazeiro. In: KIMATI, H.; AMORIM, L.; BERGAMIN FILHO, A.; CAMARGO, L. E. A., REZENDE, J. A. M. (Ed.). Manual de fitopatologia: doenças das plantas cultivadas. 4. ed. São Paulo: Ceres, 2005. v. 2, p. 467-474.

INSTITUTO BRASILEIRO DE GEOGRAFIA E ESTATÍSTICA - IBGE. Censo agropecuário 2006. 2007. Disponível em: <http://www.ibge.gov.br/home/ estatistica/economia/agropecuaria/censoagro/2006/ default. shtm>. Acesso em: 25 set. 2011.

MARSCHNER, H. Mineral nutrition of higher plants. 2. ed. San Diego: Academic Press, 1995.

MELAMED, R.; GASPAR. J. C.; MIEKELY, N. Pó de rocha como fertilizante alternativo em sistema de produção sustentáveis em solos tropicais. Brasília: Ministério da ciência e tecnologia. 2007. 26 p. Disponível em: $<$ http:// www.cetem.gov.br/publicacao/cetem_sed_72_p.pdf $>$. Acesso em: 19 jan. 2010. 
MICHALOVICZ, L.; KOLLN, O. T.; MEERT, L.; NASCIMENTO, R.; MULLER, M. M. L. Características químicas de um latossolo bruno após quatro anos de adição de pó de basalto e biofertilizante. In: CONGRESSO BRASILEIRO DE AGROECOLOGIA, 6., 2009, Curitiba. Anais... Curitiba: ABA, SOCLA, Governo do Paraná, 2009. CD-ROM.

PERUCH, L. A. M.; SCHROEDER, A. L.; COLARICCIO, A.; CHAGAS, C. M.; GUIMARÃES, L. Doenças do maracujazeiro amarelo. Florianópolis: Epagri, 2009. 99 p.

PIO-RIBEIRO, G.; MARIANO, R. L. R. Doenças do maracujazeiro. In: KIMATI, H.; AMORIM, L.; BERGAMIM FILHO, A.; CAMARGO, L. E. A.; REZENDE, J. A. M. (Ed.). Manual de fitopatologia: doenças das plantas cultivadas. 3. ed. São Paulo: Ceres, 1995. v. 2, p. 525-534.

RHEINLÄNDER, P. A.; FULLERTON, R. A.; SALE, P. Sustainable management of passionfruit disease in New Zealand. Auckland: Plant and Food Research, 2009. 40 p.
RIBEIRO JÚNIOR, J. I. Análises estatísticas no SAEG. Viçosa: UFV, 2001. 301 p.

RODRIGUES, F. A.; MACNALLY, D. J.; DATNOFF, L. E.; JONES, J. B.; LABBÉ, C.; BENHAMOU, N.; MENZIES, J. G.; BELANGER, R. R. Silicon enhances accumulation of diterpernoid phytoalexins in Rice: a potencial mecanism for blast resistance. Phytopathology, Palo Alto, v. 94, n. 2, p. 177-183, 2004.

SANTOS, J. F. dos; LEMOS, J.N.R.; ALBUQUERQUE, I. C. de; BRITO, L. M. P. Produção de goiabeira e maracujazeiro utilizando alternativa orgânica. Tecnologia e Ciência Agropecuária, João Pessoa, v. 1, n. 1, p. 15-18, 2007.

SHANER, G.; FINNEY, R. E. The effect of nitrogen fertilization on the expression of slow-mildewing resistance in knox wheat. Phytopathology, St. Paul, v. 67, n. 8, p. 1051-1056, 1977. 